\title{
Japan and America: A Comparative Study in Higher Education Development with the Influence of Financial Market
}

\author{
Tomoaki Hamanaka $^{1}$ and Takayuki Kogawa ${ }^{2}$ \\ ${ }^{1}$ Keio University, Yokohama, Japan \\ ${ }^{2}$ Waseda University, Tokyo, Japan \\ ${ }^{1}$ tomoaki.hamanaka@arc.ics.keio.ac.jp, ${ }^{2}$ takayuki@toki.waseda.jp
}

\begin{abstract}
At the turn of the century, the economic foundation of higher education in OECD countries has undergone significant changes. Financial markets have become an important factor affecting the development of higher education in the context of slowing economic growth. On the one hand, the speed of economic growth has slowed. On the other hand, "marketization" has begun to appear in the discourse related to the reform of higher education. In this regard, the United States and Japan have many similarities. The mechanism by which the financial market plays a role in higher education and its consequences, etc., There are many differences between the United States and Japan. This article describes a conceptual framework based on higher education-related factors, outlines how various factors promote changes in Japanese higher education, and how the financial market has become an important factor of participation since the turn of the century, and discusses the macro meaning of the picture for future policy directions.
\end{abstract}

Keywords: Higher education, Slowing economic growth, Expansion of higher education, Capital market

\section{Introduction}

The relationship between higher education and economic growth first attracted people's attention in the late 1950s and 1960s. During this period, the economies of OECD countries began to enter the post-war period of economic growth. At the same time, the expansion of higher education is gaining momentum. The combination of popularization of higher education and economic growth continued until the 1970s, promoting the transition of higher education from the "elite stage" to the "popular stage". This transformation constitutes the picture of the development of higher education at the end of the 20th century. Corresponding to this economic change is the development of human theory and successive human capital theory. As a result, a new field of research has been formed, the economics of education based on the theoretical concepts of human capital. Looking back, one might think that the economics of education has played a role in providing a rational basis for increasing the expenditure required for the expansion of higher education. However, by the end of the 20th century, the situation has changed significantly. As the economy matured, many OECD countries lost momentum in their economic growth [Figure 1]. At the same time, the participation rate of higher education institutions has continued to increase, entering the so-

Article history:

Received (July 17, 2019), Review Result (September 1, 2019), Accepted (October 30, 2019) 
called discourse related to the development of higher education has also changed, and the term "marketization" has begun to appear [1].

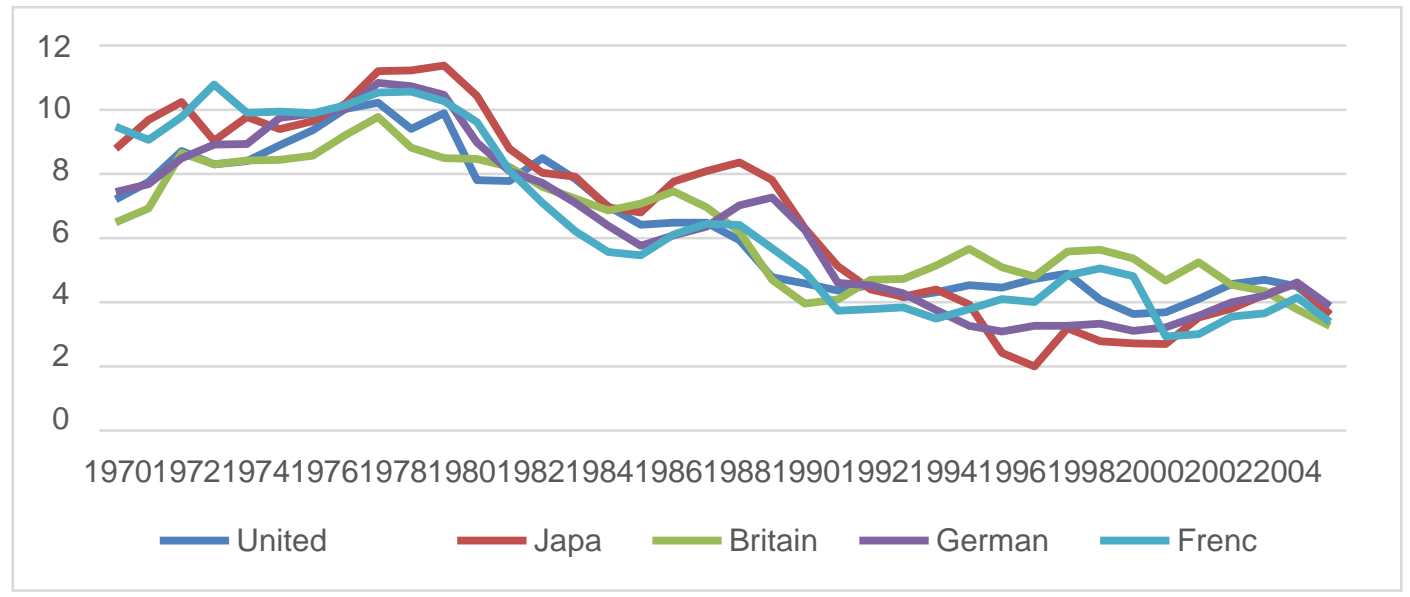

Figure 1. Changes in GDP growth rate (1970-2012)

These observations raise a series of questions. Despite the slowdown in economic growth, why is the participation rate in higher education still rising? What does the concept of marketization mean? When the transition relationship between higher education development and economic growth changes? Why "market "Hua" will become a popular term? To answer these questions, we must expand the scope of thinking to various factors that affect higher education. We also need a macro perspective. It can be recalled that the theory of human capital was originally macro, explaining society from education How much benefit from investment, although it quickly becomes the theoretical basis for analyzing individual education and training behaviour. To some extent, we must return to the initial perspective of how higher education is related to the economic development of the entire society.

From the perspective of society and the economy, the relationship between higher education and society involves various intervening factors. In addition to the government, we can also see three economic functions that regulate higher education and economic development. The first is the higher education market. The higher education opportunity market links the demand and supply of higher education opportunities with prices (tuition fees) and enrolment scale as main parameters. The second is the labour market, which links the employment opportunities of graduates or the achievements of higher education with production, and therefore affects the choice of higher education. Finally, it can be said that the increasingly important thing is the financial market, which links the accumulated monetary assets in society with higher education investment in different ways.

The demand for higher education comes from the aggregation of choices by families. Each family's choice depends on its expectations of the costs and benefits of higher education. Costs include tuition and foregone income, and benefits include expected wage differentials and non- monetary benefits obtained in the labour market. At the same time, available resources include family input, available grants, and loans. These factors are affected by the academic ability of individual students but remain the same on the whole. Supply refers to the sum of admission opportunities at different prices (tuition fees). Each institution under the constraints of available resources (including government subsidies and donations and the 
cumulative value of other income) determine a specific combination of enrolment scale and tuition pricing. The impact on both supply and demand is not only from government policies but also from the financial market through taxation. The government gives a certain amount of national income to higher education in the form of subsidies and student funding projects. At the same time, the tax system stimulates families to choose higher education and encourages individuals and businesses to make contributions to higher education institutions.

The financial market has become an important factor of participation in recent years. The financial market uses student loan programs (provided that the borrowed amount will eventually be repaid to the lender) to invest accumulated wealth in the national economy into higher education. Even if student loans are not considered, people should realize that when the government has deficits and these deficits are mainly financed by borrowing from the financial market, the financial market also indirectly provides funds for higher education. At the institution level, higher education institutions borrow from the market for infrastructure and other purposes. And store donations for financial gains.

Therefore, universities, the government, and the three markets, as well as the flow of resources and information between them, constitute a very complex picture, which is called the macro-structure of higher education finance. The configuration of this structure varies from country to country. In addition, this structure Under changes in the economic and political environment will evolve. This also means that higher education policy issues will also change accordingly.

\section{Development history of higher education}

Now we will observe the development process of higher education from the abovementioned perspective. After recovering from the destruction of the Second World War, Japanese higher education began to develop in the 1960s. The development of Japanese higher education since the 1960s is mainly It can be divided into two stages, and each stage consists of two sub-stages spanning ten to fifteen years.

\subsection{The first stage of popularization}

The 30 years from 1960 to 1990 can be called the stage of popularization of higher education. This stage is composed of two sub-stages: the expansion and the ensuing stagnation of enrolment.

Sub-stage 1-a is a period of great expansion of higher education. The participation rate of 18-year-old students in four-year colleges and universities rose from less than $10 \%$ in 1960 to $36 \%$ in 1975-an an increase of nearly $20 \%$ in fifteen years. And this growth occurred during a period of significant growth in the size of the university-age population.

The increase in enrolment is mainly caused by the increase in demand for higher education, which is driven by the unprecedented growth of household income in the context of rapid economic growth. From the early 1960s to 1980, the disposable income of typical households increased rapidly. This means that each family is equivalent to $7 \%$ or $8 \%$ of additional income each year. Since higher education is the main channel for upward social mobility, families are willing to invest the additional resources at their disposal into higher education for future generations.

On the supply side, with the establishment of some new colleges and universities, private colleges and universities have increased their enrolment. This is due to the relaxation of the "University Standards" policy. The relaxation of this policy is to respond to the general public demand for higher education. At the same time, the additional tax revenue brought about by 
economic growth has also been used to increase the number of students enrolled in natural sciences and engineering at national colleges and universities to cultivate the human resources needed for rapid economic growth.

This capital flow system has been proven to be able to effectively meet the needs of the public for higher education, and it also enables the government to focus on investing in stateowned institutions to cultivate strategic human resources needed for economic development. This system also creates an educational condition. A relatively poor large private college sector, this situation continues to this day.

During sub-phase 1-b, by 1980 , the participation rate dropped to $24 \%$. This was mainly caused by restrictive government policies on the supply side. After achieving rapid growth, the focus of government work gradually shifted from economic growth to welfare policies. In terms of higher education measures taken by the government to implement current cost subsidies for private colleges and universities (implemented in 1976). Although this policy aims to reduce the financial burden of student families who pay for tuition, it produces unexpected results as a result of.

To obtain subsidies, colleges and universities are required to control the scale of enrolment higher than the "University Standards". As a countermeasure, private colleges have reduced enrolment and increased tuition at the same time. This can be interpreted as they are trying to distinguish themselves and the strategic measures taken by less selective institutions [2].

On the demand side, considering the continued growth of household income, potential demand should continue to rise. In addition, with the arrival of the second-generation baby boom to universities, the size of the 18-year-old population increased in the late 1980s. In the limited supply under these factors, demand frustrated, which in turn translated into intensified competition for university admissions opportunities, which eventually triggered criticisms of over-regulation of higher education.

\subsection{The second stage of popularization}

Since the early 1990s, the participation rate in higher education began to increase again. This increase eventually extended to $50 \%$ in the 2010s. We call this the universalization stage. However, the growth mechanism at this stage is significantly different one stage.

Sub-phase 2-a spans the 1990s and is manifested as a steady increase in the participation rate, driven to a certain extent by the pent-up demand accumulated due to the restrictive policies on the supply side of the previous phase (1-b). At the same time, the disposable income of households is still growing, although the growth rate is much lower than before, and the demand is still being pushed forward.

On the supply side, in the context of the shift to deregulation in the early 1990s, restrictive policies have also been reversed. Some provisions of the "university standards" have been relaxed. Existing institutions of higher learning have been allowed to expand the scale of enrolment. At the same time, a large number of new colleges and universities were born, many of which were transformed from two-year private colleges or high schools. As a result, the number of students admitted has also increased. With the decline in the size of the 18year-old population, the combination of these factors has led to an increase in the participation rate [3]. During sub-phase 2-b, the participation rate continued to increase, but the driving force behind it changed significantly. This increase is confusing. Because of the slowdown in economic growth, disposable household income stagnated and eventually began to decline due to the increase in pension and medical insurance [Figure 2] contributions. 


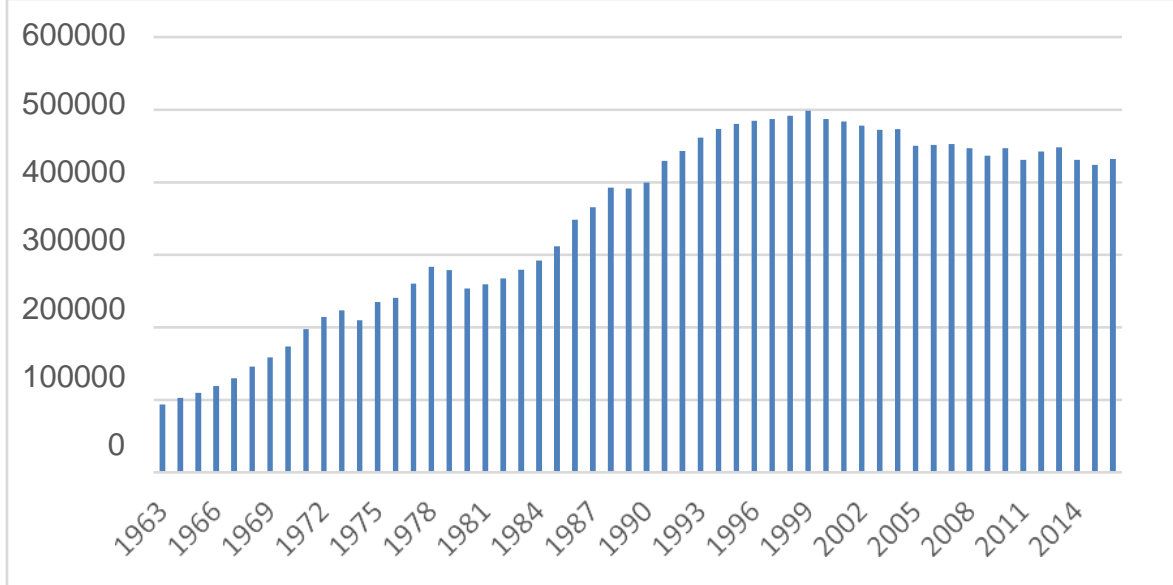

Figure 2. Changes in disposable income (households with more than two family members)

The replacement for the declining household disposable income is the use of student loans. Until the end of the 2000s, the proportion of students using JASSO loans was only slightly higher than $10 \%$. This proportion began to increase in the late 1990s. It will reach $35 \%$ by 2010 (see Figure 3). This means that not only those families that represent marginal growth in participation rates, but also families that used to rely on family income to pay tuition fees are also beginning to borrow to pay for college expenses.

It should be noted that since the mid-1980s, market interest rates have begun to fall, and eventually fell to $1 \%$ or $2 \%$ at the beginning of the 21 st century (Figure 4 ). The interest rate of student loans has also fallen to about $1 \%$ accordingly. At the same time, according to the author's estimation, the internal rate of return (IRR) of four-year university education is still as high as $6 \%$ to $7 \%$. This means that even if you need to pay the necessary costs through loans, you can still get financial returns from going to university. Higher education returns gap between them then widened rapidly [4].

These observations show that since the 21st century, factors related to financial markets have begun to play an important role, triggering important changes in the flow of resources in the macrostructure.

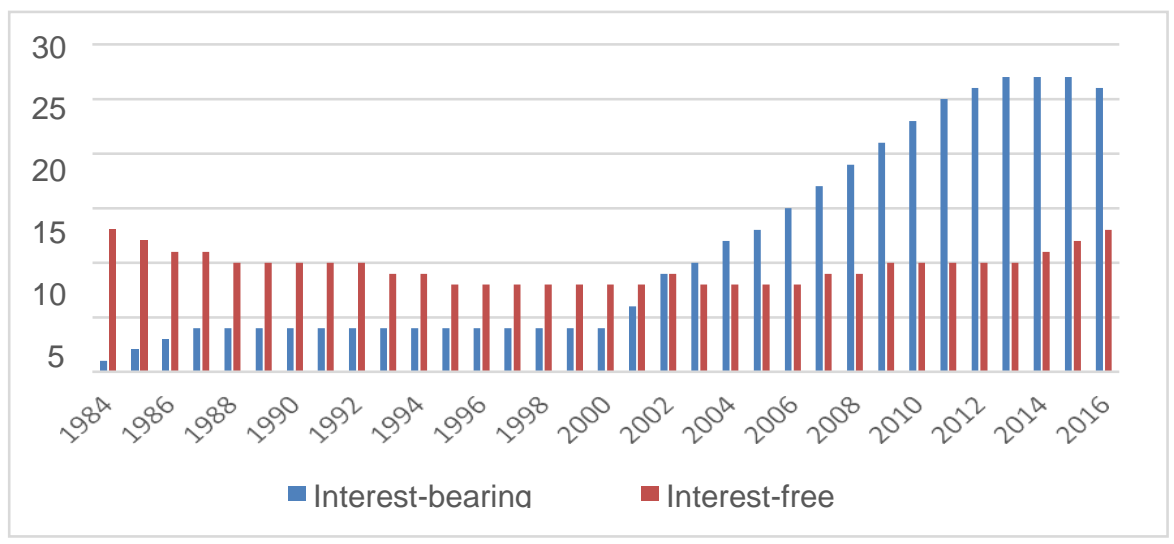

Figure 3. The proportion of students using JASSO loans (\%) 


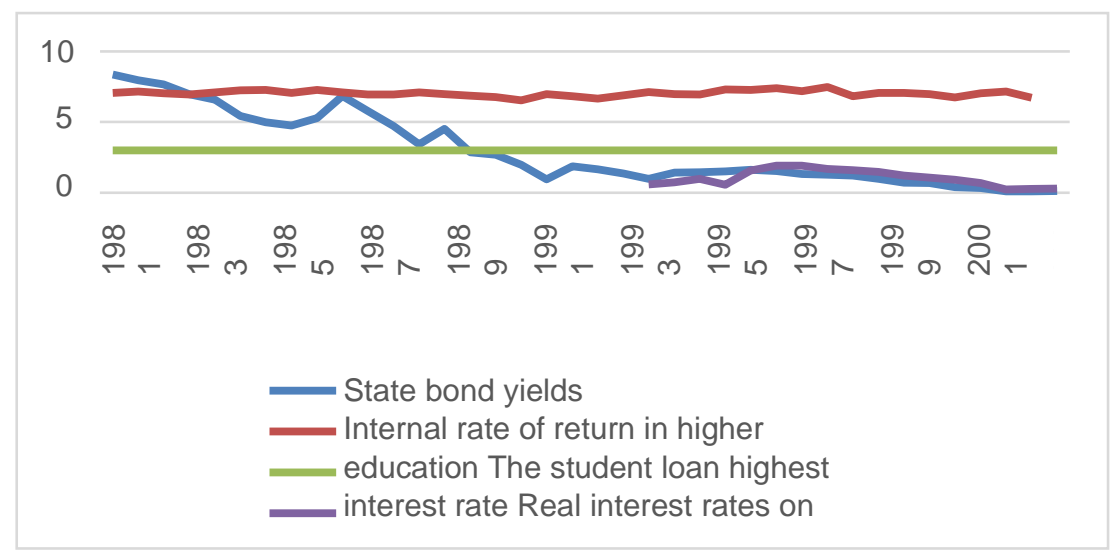

Figure 4. Higher education internal rate of return, student loan interest rate, and market interest rate

\subsection{Economic growth slowdown and higher education}

It should be noted that borrowing from the financial market in higher education began to appear in recessive form in the early 1980s. During this period, the state budget began to have huge deficits, and this deficit was borrowed from postal savings and distribution. This means that as part of the national budget, the government's expenditure on higher education comes from the capital market indirectly. The increase in student loans with individuals as beneficiaries means that borrowing from the capital market - the financing method that supports higher education - has become more dominant.

In addition, there are funds available in the market to provide student loans at relatively low- interest rates. This type of funds includes the currency assets accumulated by individuals and commercial companies, which are generated by past economic growth plus relatively high savings rates and low taxes. burden. These savings are deposited in banks, and banks not only invest these deposits in companies but also lend them to the government in the form of national bonds. In addition, a large proportion of these assets are invested in overseas financial institutions. According to estimates, as of 2018, Japan's total household assets reached 1,800 trillion yen, which is three times Japan's GDP or 18 times the national budget.

People may remember that the role of the financial market in higher education is particularly prominent in the United States, especially after the end of the 1980s. In the context of economic stagnation and stagnant population growth at university age, private colleges continue to increase tuition and admissions Policies to highlight oneself. The use of student loans has begun to expand dramatically. This will be discussed later. This mechanism has laid the foundation for the transformation of American higher education in the past three decades.

\section{Innovation in higher education}

\subsection{Fairness}

Social concern. All political parties have included some measures to address this issue in their 2017 general education program. The ruling Liberal Democratic Party won the election with a proposal of "free higher education". The Abe government has been working hard to formulate specific measures afterward, but Details remain to be seen. 
This renewed attention is driven by many factors. First of all, four-year higher education has reached the stage of universalization, which means that half of the school-age youth can receive higher education, and university education is no longer regarded as a choice but a necessity The lack of higher education is considered to be a disadvantage to the individual. Ensuring the opportunity to receive higher education has become a serious concern for any parent.

Second, social deprivation has received widespread attention. If children from low-income families are unable to obtain higher education opportunities due to economic reasons, this will have a serious impact on social justice.

The loan repayment situation. Especially for college students who graduated a few years before 2010, they are facing an oversupply of the labour market, and a large number of students are unable to find employment upon graduation. Because the principle of permanent employment is dominant in employment practice, they have not been able to enter upon graduation. Career paths often lead to instability in lifelong employment. These graduates are in a particularly difficult situation in repayment, sometimes leading to extreme poverty. After these cases were reported in the media, the public's negative sentiment towards student loans began to appear.

Equity concerns are constructed by various events and interests. In this case, the key question will be whether or how the government should play a role in responding to these social issues.

The most straightforward solution is to increase government spending on higher education to eliminate the impact of parents' income. At present, the government provides financial support for state-owned institutions and subsidies for private institutions. By increasing subsidies, people expect that the level of tuition fees should fall, thereby reducing the impact of household income. However, private institutions will not reduce the level of tuition due to increased subsidies. In addition, various surveys have shown that before entering higher education, differences in admission opportunities are related to academic performance that is affected by family income.

Another method is to directly provide subsidies to students from low-income families in the form of subsidies. A basic problem of this method is how to choose the target of the subsidy. The budget restricts large-scale expenditures for this purpose. On the other hand, restricting the subsidy group too narrow will lead to many difficulties, because this will not only cause various technical problems in defining and identifying the target but also Cause conflicts between beneficiaries and others.

These discussions ultimately focused on how the marginal growth of government spending can effectively correct educational inequities in a broader context. Various survey results show that the proportion of children from low-income families participating in higher education is indeed low [5]. However, a survey showed that among high school students with excellent academic performance, the difference in higher education participation rates of different income families is relatively small. These students expect to obtain high returns through higher education and are looking for ways to break through financial constraints. From this perspective, student loans are effective. The difference in family income is more prominent among students with lower academic performance.

From this perspective, most of the differences in university participation rates stem from differences in academic performance levels that occurred before entering higher education. This point shows that differences in academic performance are produced in the early stages of education. A consensus is to invest in elementary education and even pre-school education, the use of resources is more efficient [6]. 
So, what role can the capital market play in higher education equity? The student loan program cannot eliminate the intergenerational transmission of income inequality, and its role seems to be insignificant. After all, students with loans must repay this debt after graduation, which means that their net income after graduation will be lower than the net income of graduates from wealthy families (without loans).

Nevertheless, student loans can allow students with limited income to receive higher education and the consequent higher income, and obtain a certain degree of return after debt repayment. If the internal rate of return of higher education is still higher than the loan Interest rate, which is equivalent to a substantial increase in net income. In addition, student loans can allow individuals to choose higher education. This is the classic argument of Milton Friedman [7].

However, the loan project itself has some problems, such as risk aversion. Some people claim that low-income families tend not to use loans because they tend to avoid applying for loans that cannot be repaid. But this statement has no empirical basis, and our survey data on high school students do not indicate this tendency.

Nevertheless, student loans do bring risks to lenders and discourage students from using loans, which is of great significance. As mentioned above, cases of serious problems in the loan repayment process are worrying. Using loans instead of government expenditures, after all, means that the individual should make the choice, and the consequences are borne by the individual. However, extreme penalties must be avoided. The government should play a key role in this.

\subsection{Efficiency}

Another key point is how to effectively use national wealth to achieve future growth. As mentioned above, the internal rate of return (IRR) of higher education is estimated to be around $7 \%$. For the sake of accuracy, this internal rate of return should be adjusted based on income tax to obtain a private rate of return, or adjusted based on government expenditure to obtain a social rate of return. However, in either case, the difference caused by the adjustment will not exceed $1 \%$. The internal rate of return of higher education is much higher than other investment options.

At the same time, since the 21st century, interest rates on national bonds and bank deposits have fallen sharply. This reflects international trends to a certain extent, but the situation in Japan is particularly prominent. Part of the reason is that the monetary policy adopted to stimulate economic growth also reflects the changes in the relationship between capital supply and demand. On the one hand, past economic growth has accumulated a lot of savings. It is estimated that the total monetary assets in 2017 reached 1,800 trillion yen, which is 3 times Japan's GDP or 18 times the national expenditure. On the other hand, investment opportunities have not achieved corresponding growth. Therefore, the excess capital supply turns to seek overseas investment opportunities. At present, Japan's total overseas net monetary assets exceed 300 trillion yen, ranking first in the world.

Based on these considerations, we can argue that investment in higher education is not only beneficial to individuals, but also society as a whole. Because the social rate of return of higher education is higher than the current interest rate, Yano [8] believes that the government should devote more resources to higher education. This conclusion is not necessarily trivial.

First of all, high returns mean that investing in higher education can improve the state of society as a whole, but the government should not directly subsidize higher education 
institutions to increase higher education expenditures. If there is a huge fiscal deficit, this measure is impractical. Another alternative is for the government to introduce and use the wealth accumulated in the national economy through the financial market. This has become one of the important channels for higher education financing.

\subsection{Higher education innovation and market}

However, the use of financial markets requires a key condition, that is, investment in higher education can be rewarded. It is worth noting that the internal rate of return of higher education is calculated based on the current salary structure of college and high school graduates. If this point undergoes any major changes in the future, the actual rate of return will increase or decrease and the latter may become a reality.

So far, in Japan, the ability related to wage levels has been formed in the process of accumulating and sharing the skills and knowledge required in the work. And this is achieved through the lifetime employment system. A large part of the contribution of university education is to identify young people with appropriate basic abilities to participate in informal training in the workplace. This mechanism is now facing major challenges. New industrial fields are emerging, and they require different knowledge and skills. At the same time, corporate organizations are constantly reforming themselves. In the fierce international competition, companies no longer make long-term plans to invest in labour. All these factors make the existing productivity mechanism quickly eliminated. Higher education is required to teach relevant knowledge and abilities to fill this gap.

Nevertheless, so far, institutions of higher learning have not responded to these challenges. When a commercial company recruits students, it is not based on what they have learned at the university, but on the ranking of their school. Because the high selectivity of universities constitutes a steep hierarchical structure, they are not very interested in improving education.

At the same time, many private institutions are still plagued by poor education conditions, such as the high ratio of students to faculty. In large-scale private colleges, the ratio of students to faculty in the School of Social Sciences tends to reach 30 or even higher. This phenomenon is not uncommon. These practical conditions have severely weakened innovation efforts. On the other hand, since the 1990s, many private universities, large and small, have been working hard to expand their enrolment and set up new colleges and courses to cater to emerging academic fields. This phenomenon has been explained as a phenomenon of ensuring financial investment and attracting the means of students. In other words, the market and government policies have little incentive to increase tuition to improve educational conditions. At the same time, the decline in the 18 -year-old population has made it impossible for any college to continue to expand.

From this perspective, the development of the United States since the 1980s is very interesting. During this period, many private colleges reduced the number of admissions to increase their selectivity, and at the same time increased tuition as a compensation measure [9][10][11]. The increased tuition can be paid for through federal and other student loans. At the same time, colleges and universities provide outstanding students with grants to offset their high tuition fees. Universities can use their donated income to provide financial support for these bursaries, which is of great significance in refuting the critical view that bursaries come from tuition fees paid by other students. In this relationship, it should also be noted that the Reagan administration promoted a major reform of the tax system, and the appreciation of currency assets can be greatly deducted. This creates a strong incentive for private donations from colleges and universities when the stock price rises in the later period [12]. 
For many reasons, the changes produced through this mechanism have been criticized. In the past two decades, tuition fees have more than doubled, and the financial burden on students to repay loans has increased correspondingly. On the other hand, this mechanism seems to create an environment where universities compete with each other for recruiting talented students and innovative education. It can be said that the leading universities in the United States have made brilliant achievements in this way and have caused other universities to follow suit.

\section{Conclusion}

Since the turn of the century, the financial market has become an important factor affecting the development of higher education under the background of slowing economic growth. In this regard, the United States and Japan have many similarities. However, there are many differences between the United States and Japan in terms of the mechanism by which the financial market plays a role in higher education and its consequences. The key factor is how colleges and universities act in these situations. Will similar changes happen in Japan? What are the necessary conditions for change? Considering fairness and efficiency, is this change desirable? Will it trigger necessary changes in Japanese higher education? These are when choosing the future development direction of Japanese higher education Questions that must be answered.

\section{References}

[1] Bank of Japan, Flow of funds accounts,3rd Quarter, (2018)

[2] M. Kaneko, "Japanese higher education and the state in transition," In Roger Goodman, Takehiko Kariya, \&John Taylor (Eds.), Higher education and the state Oxford, Symposium Books, pp.171-198, (2018)

[3] M. Kaneko," Higher education policies and development: Approaches to funding higher education in Japan," In Armstrong, Shiro, \&Chapman, Bruce (Eds.), Financing higher education and economic development in East Asia (). Canberra, Australian University Press, pp.107-142, (2011)

[4] M. Kaneko, "Enrollment expansion in Postwar Japan," 111 pages, R.I.H.E.

[5] M. Kobayashi, Daigaku Shingakuno Kikai (Opportunity of higher education), University of Tokyo Press, (2009)

[6] J. J. Heckman, "Schools, skills, and synapse," Economic Inquiry, vol.46, no.3, pp.289-324, (2008)

[7] M. Friedman and R. Friedman, "Free to choose," New York: Harcourt Brace Jovanovich

[8] M. Yano, "Kyouiku Retsui Shakai Society (Low priority on education in the Japanese society)," Iwanami Shoten, (2016)

[9] R. Geiger, "Knowledge and money: Research universities and the paradox of the marketplace" Stanford University Press, (2004)

[10] C. M. Hoxby, "How the changing market structure of U.S. higher education explains college tuition," NBER Working Paper, 6323

[11] D. Kirp, "Financing American higher education in the era of globalization," Harvard University Press, (2004)

[12] W. Zumeta, D. W. Breneman, P. M. Callan, and J. E. Finneye, "Financing American higher education in the era of globalization,” Journal of Higher Education, vol.84, no.3, pp.446-448, (2013) 